\title{
Bilateral internal iliac artery ligation: the procedure of choice in life threatening postpartum haemorrhage
}

\author{
Sameer P. Darawade ${ }^{1}$, Arti A. Wagle ${ }^{1 *}$, Sneha Trivedi $^{2}$, Saloni Manwani ${ }^{1}$
}

\begin{abstract}
${ }^{1}$ Department of Obstetrics and Gynecology, Smt. Kashibai Navale Medical College and General Hospital, Pune, Maharashtra, India

${ }^{2}$ Department of Obstetrics and Gynecology, Noble Hospital, Pune, Maharashtra, India
\end{abstract}

Received: 22 September 2019

Revised: 27 July 2020

Accepted: 03 August 2020

\section{*Correspondence:}

Dr. Arti A. Wagle,

E-mail: artiwagle@gmail.com

Copyright: ( ) the author(s), publisher and licensee Medip Academy. This is an open-access article distributed under the terms of the Creative Commons Attribution Non-Commercial License, which permits unrestricted non-commercial use, distribution, and reproduction in any medium, provided the original work is properly cited.

\section{ABSTRACT}

Background: The present study was to assess the indication and study the intraoperative and postoperative complications of bilateral internal iliac artery ligation. Aim of this study was to evaluate the effectiveness of internal iliac artery ligation in arresting postpartum haemorrhage.

Methods: This is a retrospective study carried out between January 2015 to December 2018 at Shrimati Kashibai Navale Medical College and General Hospital, Pune. This study included 48 patients with life-threatening PPH. Bilateral internal iliac artery ligation was done by anterior approach in 7 patients and by posterior approach in 41 patients.

Results: Intraoperative and postoperative complications were noted in all patients. Of the total patients, 10 required massive blood transfusion and 12 underwent obstetrical hysterectomies $(n=12 ; 25 \%)$. Internal iliac vein injury was seen in 1 patient $(n=1 ; 2.08 \%)$ and external vein thrombosis was noted in 3 patients $(n=3 ; 6.25 \%)$. Maternal mortality was observed in 1 patient due to DIC on day $9(n=1 ; 2.08 \%)$. The uterine salvage rate was $75 \%$.

Conclusions: Internal iliac artery ligation (IIAL) safe, rapid, effective, time tested method of controlling bleeding from genital tract.

Keywords: Internal iliac artery ligation, Maternal morbidity, Maternal mortality, Obstetric hysterectomies, Postpartum haemorrhage, Uterine salvage

\section{INTRODUCTION}

Postpartum haemorrhage (PPH) is defined is defined as bleeding from or into the genital tract of more than 500 $\mathrm{ml}$ in vaginal delivery and more than $1000 \mathrm{ml}$ in caesarean section within 24 hours. It can occur up to 6 weeks postpartum.

Bleeding of more than $1000 \mathrm{ml}$ in vaginal delivery and $1500 \mathrm{ml}$ in caesarean constitutes life-threatening PPH. It is one of the leading causes of maternal mortality and long-term morbidity. ${ }^{1}$ It is reportedly responsible for over
$1,25,000$ maternal deaths each year and is associated with morbidity in 20 million women per year. ${ }^{2}$

PPH can cause exsanguination rapid enough to be fatal in spite of availability of blood products. ${ }^{3,4}$ This procedure has withstood the test of time. It is not only effective for atonic but also for traumatic PPH. ${ }^{5}$

Howard Kelly first pioneered the ligation of the internal iliac artery in 1893 for controlling intraoperative bleeding from cervical cancer. This procedure was later researched upon by Burchell in 1968 and has been practised ever 
since. The major indications for internal iliac artery ligation include atonic or traumatic postpartum haemorrhage, adherent placenta, rupture uterus, placenta praevia and abruptio placenta. ${ }^{6}$

This method is life-saving in cases where there is failure of conventional methods to prevent bleeding. The reported success rate of IIAL varies from 40 to $100 \%$. $^{7}$

The hypogastric artery distal to the point of ligation is never emptied of blood because the rich anastomotic network starts to function immediately after ligation. Internal iliac ligation causes reduction in: pulse pressure by $85 \%$ blood flow by $50 \%$ and mean arterial pressure by 25 to $50 \% .^{8}$

The ligation converts arterial system into venous system leading to stable clot formation thus bring haemostasis.

\section{METHODS}

This is a retrospective study carried out between January 2015 to December 2018 at Shrimati Kashibai Navale Medical College and General Hospital, Pune. This study included 48 patients with life-threatening PPH. Bilateral internal iliac artery ligation was done by anterior approach in 7 patients and by posterior approach in 41 patients.

All cases of internal iliac ligation done in view of PPH from January 2015 to December 2018.

Prophylactic IIAL was performed in women with a highrisk of developing $\mathrm{PPH}$.

Patients were initially treated with uterine massage and uterotonics such as oxytocin infusion and carboprost 250 mcg injections. Failure of these methods to arrest bleeding led to the decision of performing therapeutic IIAL.

Patients were followed up for postoperative complications.

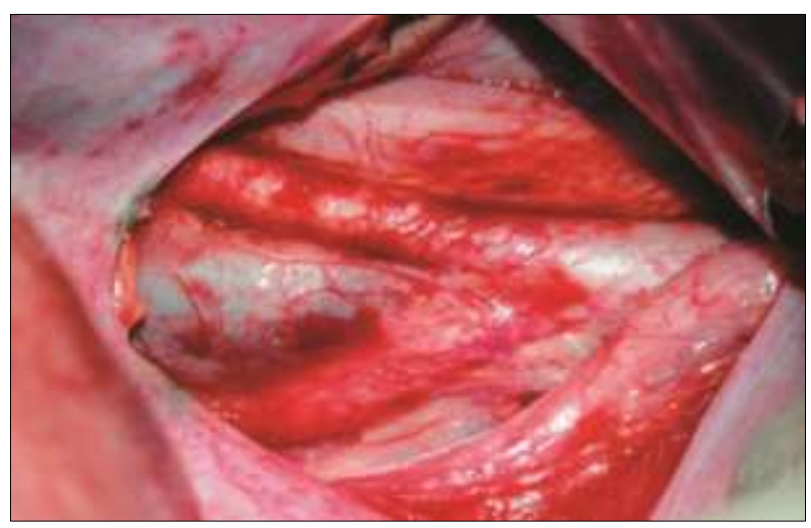

Figure 1: Bifurcation of common iliac into internal and external iliac. ${ }^{9}$

\section{Operative technique}

All patients underwent IIAL through an existing incision under spinal/general anesthesia given for primary surgery. The puerperal uterus was moved anteriorly and the bowels were packed away. Both the ureters were identified at the pelvic brim along with the bifurcation of the common iliac artery into internal and external iliac (Figure 1).

The peritoneum was incised craniocaudally distal to the bifurcation in between the infundibulopelvic and uterosacral ligament. The ureter was kept attached to the medial fold of peritoneal reflection.

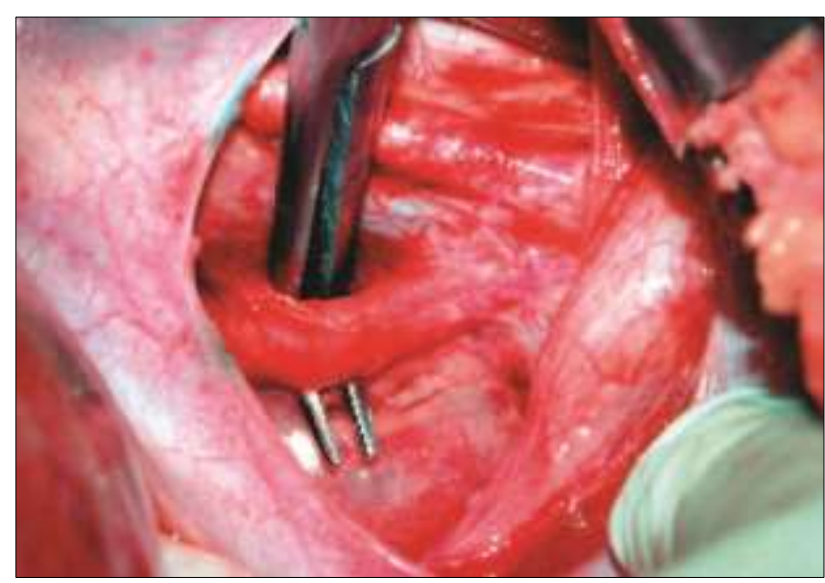

Figure 2: Mixter forceps passed from lateral to medial side. ${ }^{9}$

Internal iliac was traced downwards and the fascia over the artery is dissected away. After identification and isolation of the iliacs, mixter forceps was passed from lateral to medial side about $3 \mathrm{cms}$ away from the bifurcation (Figure 2). Before ligation, the artery was confirmed by palpating the pulsations of the femoral artery.

Authors used vicryl number 1 for the ligature. The artery was ligated at 2 places. Hemostasis was confirmed. Abdomen was closed as usual.

\section{Statistical analysis}

The data on categorical variables is shown as $\mathrm{n}(\%$ of cases). All results are shown in tabular as well as graphical format.

\section{RESULTS}

In the present study, there were 48 patients with life threatening PPH who underwent bilateral internal Iliac artery ligation.

The most common indication for therapeutic PPH in this study was placenta praevia followed by uterine atony and 
abruptio placentae. Bilateral extension of the incision leading to rupture of the uterine arteries followed by excessive bleeding was the $4^{\text {th }}$ most common indication (Figure 3).

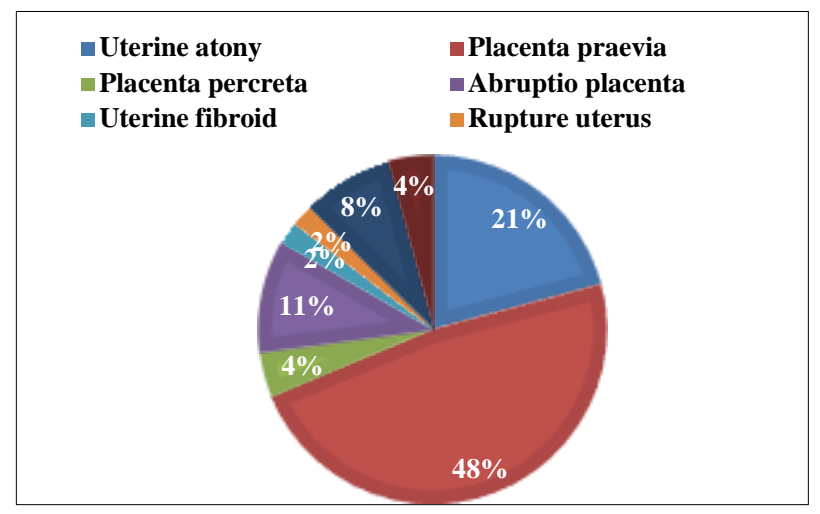

Figure 3. Indications of bilateral internal iliac artery ligation.

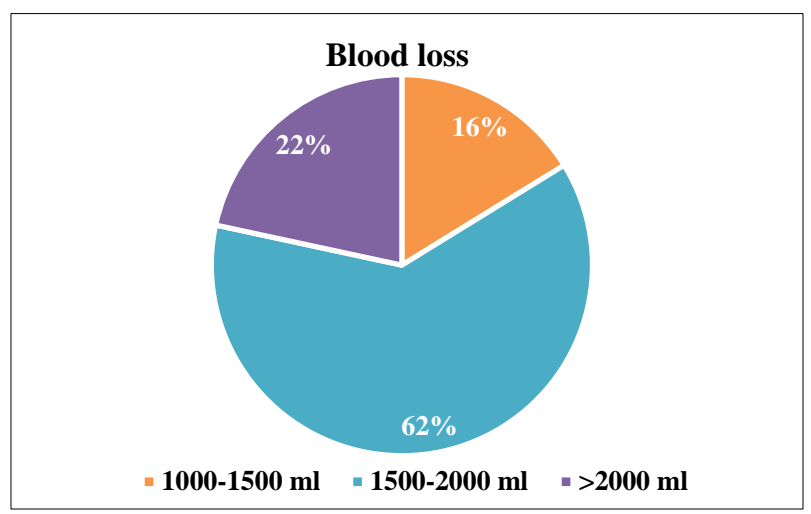

Figure 4: Blood loss from PPH.

The range of blood loss for which internal iliac ligation was done was 1500-2000 ml (Figure 4).

1 unit includes 1 unit of PCV, 1 unit of FFP and 1 unit of platelets

The maximum units of blood required in this study was 8 . Most of the patients were haemodynamically stable when transfused between 2-4 units (Table 1).

Table 1: Blood transfusion.

\begin{tabular}{|ll|}
\hline Blood product & No. of patients \\
\hline $\mathbf{2 - 4}$ units & 22 \\
\hline 4-8 units & 15 \\
\hline $\mathbf{> 8}$ units & 11 \\
\hline
\end{tabular}

Out of the 48 cases, bleeding was arrested in 36 cases $(75 \%)$. The remaining 12 underwent obstetrical hysterectomies $(25 \%)$.

Out of these 12 patients, the number of patients who underwent obstetrical hysterectomy before internal iliac artery ligation was $8(66.66 \%)$ whereas the number of patients who underwent obstetrical hysterectomy even after ligation of internal iliac was 4 (33.33\%) (Table 2).

Table 2: Hysterectomy.

\begin{tabular}{|ll|}
\hline Obstetrical hysterectomy & $\begin{array}{l}\text { No. of patients } \\
(\%)\end{array}$ \\
\hline Prior to IIAL & $8(66.66)$ \\
\hline After IIAL & $4(33.33)$ \\
\hline
\end{tabular}

Table 3: Postoperative complications.

\begin{tabular}{|ll|}
\hline Complications & $\begin{array}{l}\text { No. of patients } \\
(\%)\end{array}$ \\
\hline External iliac vein injury & $0(0)$ \\
\hline Internal iliac vein injury & $1(2.08)$ \\
\hline Ligation of wrong structure & $0(0)$ \\
\hline External iliac vein thrombosis & $3(6.25)$ \\
\hline $\begin{array}{l}\text { Maternal mortality (D9 due to } \\
\text { DIC) }\end{array}$ & $1(2.08)$ \\
\hline
\end{tabular}

The most common complication encountered in this study was external iliac vein thrombosis. There was 1 maternal mortality on day 9 due to disseminated intravascular coagulation (Table 3).

Table 4: Parity in association with internal iliac artery ligation.

\begin{tabular}{|l|l|}
\hline Parity & No. of women \\
\hline Primigravida & 14 \\
\hline $\mathbf{2}$ & 17 \\
\hline $\mathbf{3}$ & 15 \\
\hline $\mathbf{> 4}$ & 2 \\
\hline
\end{tabular}

The maximum incidence of internal iliac artery ligation due to PPH was observed in gravida 2 followed by gravida 3. Multigravida i.e., women conceiving more than or equal to 4 had a comparatively lesser incidence of undergoing internal iliac artery ligation (Table 4).

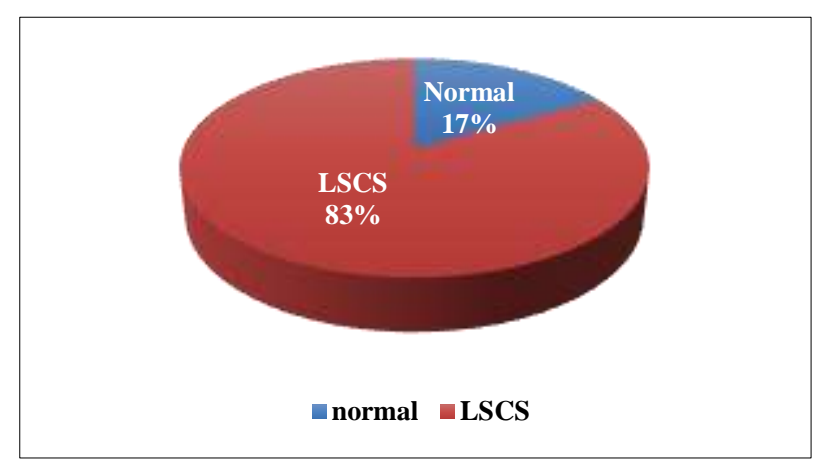

Figure 5: Type of delivery.

Lower segment caesarean section had the maximum incidence of internal iliac artery ligation (84\%) (Figure 5). 


\section{DISCUSSION}

The effectiveness of this study has been evaluated in terms of uterine salvage rate $(75 \%)$. This is comparable to the studies conducted by Mukherjee et al (83.3\%), Joshi et al (60.7\%) and Nayak et al (73.4\%) and is significant. $^{10-12}$

Number of cases that had to be reopened for exploration post bilateral internal iliac artery ligation which in this study were nil.

Control of PPH with bilateral internal artery ligation alone.

PPH can cause exsanguination rapid enough to be fatal in spite of availability of blood products. India is amongst those countries which have a very high maternal mortality rate of which PPH accounts for the single most common cause.

In this study it was noted that internal iliac artery ligation is a safe, effective and easy way to control PPH. Although, uterine artery ligation is an excellent technique of controlling PPH, in cases such as avulsed uterine artery, IIAL is a useful method.

IIAL not only prevents obstetric hysterectomies but also in cases where hysterectomy cannot be prevented, it facilitates hysterectomy as in cases of uterine trauma. It decreases the bleeding into the operative field, thereby enabling the surgeon to prevent blindly clamping the pedicles thereby reducing injury to the ureter. Once the bleeding is controlled by IIAL, it does not recur in the postoperative period.

Early resort to IIAL is the key to prevent PPH.

\section{CONCLUSION}

There are various techniques for controlling PPH which includes uterine compression and massage, pressure balloon (Bakri balloon) uterine compression sutures (BLynch), arterial embolization etc;

However, internal iliac artery ligation is the best method of arresting PPH as it not only helps counteract atonic PPH but also traumatic PPH which is not possible with any other method.

Funding: No funding sources Conflict of interest: None declared

Ethical approval: The study was approved by the Institutional Ethics Committee

\section{REFERENCES}

1. Khan KS, Wojdyla D, Say L, Gulmezoglu AM, VanLook PF. WHO analysis of causes of maternal death: a systematic review. Lancet. 2006;367:106674.

2. Selo-Ojeme DO. Primary postpartum haemorrhage. J Obstet Gynecol. 2002;22:463-9.

3. Reich WJ, Nechtow JR. Ligation of internal iliac (internal iliac) arteries: a life-saving procedure for uncontrollable gynaecologic and obstetric haemorrhage. J Int Coll Surg. 1961;36:157.

4. Reich WJ, Nechtow JR, Keith L. Supplementary report on internal iliac artery ligation in the prophylactic and active treatment of haemorrhage in pelvic surgery. J Int Coll Surgeons (Bull). 1965;44:1.

5. Cruishank SH. Management of postpartum and pelvic haemorrhage. Clin Obstet Gynecol. 1986;2:213-9.

6. Arulkumaran S, De Cruze B. Surgical management of severe postpartum haemorrhage. Curr Obstet Gynecol. 1999;8:101-5.

7. Burchell RC. The physiology of the internal iliac ligation. J Obstet. Kelly HA. Bull. John Hopkins Hospital. 1893;5:53.

8. Chattopadhyay SK, Deb Roy B, Edrees YB. Surgical control of obstetric haemorrhage: hypogastric artery ligation or hysterectomy? Int J Obstet Gynaecol. 1990;32:345-51.

9. Joshi VM, Otiv SR, Majumder R, Nikam YA, Shrivastava M. Internal iliac artery ligation for arresting postpartum haemorrhage. Int $\mathbf{J}$ Obstet Gynaecol. 2007;114(3):356-61.

10. Mukherjee P, Biswas P. Compression suture in postpartum hemorrhage. J Obstet Gynaecol Ind. 2003;53:158-9.

11. Joshi VM, Otiv SR, Majumder R, Nikam YA, Shrivastava M. Internal iliac artery ligation for arresting postpartum haemorrhage. BJOG. 2007;114:356-61.

12. Nayak AK, Dhivya S, Nayak R, Mandpe $P$. Emergency internal iliac artery ligation in control of postpartum hemorrhage: a life-saving procedure. Int J Sci Stud. 2017;4(12):183-6.

Cite this article as: Darawade SP, Wagle AA, Trivedi S, Manwani S. Bilateral internal iliac artery ligation: the procedure of choice in life threatening postpartum haemorrhage. Int J Reprod Contracept Obstet Gynecol 2020;9:3607-10. 